\title{
Diagnostic hystero-laparoscopy in work-up of female infertility
}

Amrita Rai*, Manju G. Mishra

Department of Obstetrics and Gynecology, MGM Hospital and Research Centre Pvt. Ltd., Patna, Bihar, India

Received: 24 May 2017

Accepted: 27 May 2017

\section{*Correspondence:}

Dr. Amrita Rai,

E-mail: dr.amrita.amit@gmail.com

Copyright: () the author(s), publisher and licensee Medip Academy. This is an open-access article distributed under the terms of the Creative Commons Attribution Non-Commercial License, which permits unrestricted non-commercial use, distribution, and reproduction in any medium, provided the original work is properly cited.

\section{ABSTRACT}

Background: Infertility is a growing concern of the society. In many cases the exact cause of infertility may not be elucidated, whether it is tubal, ovarian, uterine, or a combination of factors. This paper aims to understand the role of diagnostic hystero-laparoscopy in evaluation of cases of infertility.

Methods: This prospective study included 200 infertile women and it was conducted at department of Obstetrics and Gynaecology, MGM Hospital, during the period between January 2016 to December 2016. All the infertile patients either with primary or secondary infertility were included after thorough evaluation.

Results: Out of 200 cases, $118(59 \%)$ patients had primary infertility and $82(41 \%)$ had secondary infertility. While laparoscopy detected abnormalities in $49 \%$ of the cases, significant hysteroscopy findings were noted in only $23.5 \%$ of cases. The most common laparoscopic abnormalities were endometriosis (32\%) and unilateral tubal lockage (24\%). On hysteroscopy, periosteal adhesions were the commonest abnormality in both the groups.

Conclusions: Diagnostic hystero-laparoscopy is a safe and cost-effective method and should be considered when there are abnormal HSG results, a past history of pelvic infection, pelvic surgery and /or unexplained secondary infertility during management of infertile couple. Evaluation of certain significant and correctable tubo-peritoneal and intrauterine pathologies which are usually missed by other imaging modalities, can be diagnosed as well as managed in some cases by hystero-laparoscopy.

Keywords: Endometriosis, Hysteroscopy, Infertility, Laparoscopy, Pelvic adhesions

\section{INTRODUCTION}

Infertility is a common public health problem. It is defined as the inability to conceive after one year of frequent unprotected regular intercourse. 60-80 million couples all over the world are subfertile. $10-15 \%$ of reproductive-age married couple are considered infertile. ${ }^{1}$ Infertility can be primary in which case the woman has never conceived before or secondary when there is prior conception irrespective of the outcome of the pregnancy. ${ }^{2-4}$

Hysterosalpingography (HSG) was a common traditional method to assess the tubal patency and uterine cavity but it has now become largely replaced by easy procedure e.g laparoscopy due to its benefits and less complications. In addition, the focus of treatment for infertility has shift ed from the systematic correction of each identified factor to applying the most efficient therapy, which may be ART (Speroff and Fritz 2011). ${ }^{5}$ The most common initial diagnostic tests for the evaluation of an infertile couple are the mid-luteal phase progesterone assay; a test for tubal patency, such as hysterosalpingography (HSG) for females and semen analysis for males. Laparoscopy is reserved for further diagnosis or may be used in combination with endoscopic surgery (Crosignani and Rubin 2000). ${ }^{6}$ Therefore, ART may be performed on suboptimally investigated couples. In cases of treatment failure or ART failure, secondary invasive diagnostic approaches, such as 
laparoscopy, are typically performed. The most important advantages of a limited evaluation of infertile couples, which excludes laparoscopy in the diagnostic work-up, are the prevention of a delay in treatment and minimal initial testing. However, a disadvantage of this approach is that abnormalities that are associated with subfertility can be overlooked.

Laparoscopy is a minimally invasive technique and alternative option for carrying out many operations that previously required an open approach. But diagnostic laparoscopy is most appropriate and acceptable procedure to detect abdominal and pelvic pathology. Diagnostic laparoscopy also termed as exploratory laparoscopy is usually established as the most perfect and accurate procedure to detect pelvic organ pathologies likes tubal pathology, endometriosis, fibroids, ovarian cysts and other conditions influencing fertility and it allows magnified view of internal ws intraabdominal examination of appendix, gallbladder, stomach and liver. ${ }^{2-4,7-10}$ It is useful in taking biopsies of abdominal and pelvic growth as well as lymph nodes and culture acquisition and variety of therapeutic intervention. Diagnostic Laparoscopy is a minimal invasive technique that gives pelvic organs and provides information on the status of the fallopian tubes, ovaries and uterus. It is considered as gold standard for the diagnosis of various diseases e.g; pelvic inflammatory disease, endometriosis, cysts, pelvic congestion, fibroids and tuberculosis. ${ }^{9}$ Laparoscopy is used to determine the cause of pelvic pain, acute abdomen or gynecological symptoms that cannot be confirmed by physical examination or ultrasound. It is useful staging tool for certain cancers. Because of the cost and invasive nature of laparoscopy it should not be the first test in the couple's diagnostic evaluation. In general semen analysis, hysterosalpingogram (HSG), assessment of ovarian reserve and documentation of ovulation should be assessed prior to consideration of laparoscopy. However, diagnostic laparoscopy is final step in determining the optimal management plan for infertility after standard infertility screening tests. With the recent advances in fibro-optics and techniques the results of laparoscopy are encouraging. The main advantages of diagnostic laparoscopy over the traditional open laparotomy are reduced mortality, decreased postoperative pain and shorter hospital stay. Diagnostic laparoscopy is thus essential in determining the optimal management plan.

Similarly, visualizing the uterine cavity and identifying the possible pathology has made hysteroscopy an equally important tool in infertility evaluation. Combining hysteroscopy with laparoscopy has become a standard tool of evaluation though the absolute role of hysteroscopy in unexplained infertility is yet to be elucidated. ${ }^{11-14}$ This study aims to understand the role of diagnostic hysterolaparoscopy in evaluation of cases of female infertility.

\section{METHODS}

This prospective study was carried out between January 2016 to December 2016 at the Department of Obstetrics and Gynaecology, MGM Hospital. It included 200 cases of infertility (both primary and secondary) who reported to the infertility opd of this hospital.

After thorough gynecological examination and with all necessary investigations (husband semen analysis, baseline endocrinal investigations, post coital study, cervical mucus study, ovulation study, post menstrual HSG) patients were admitted a day before surgery.

Written consent was taken from all the patients. All the patients were kept fasting after $10 \mathrm{pm}$ a day before surgery. Enema was given in morning at 6:00 am. They were advised to void completely before entering the operation room. The diagnostic hystero-laparoscopies were performed under general anaesthesia with endotracheal intubation and were maintained on gas, oxygen and halothane.

Once laparoscope was introduced, the pelvic organs are first inspected (by manipulating uterus, tubes, ovaries, pouch of Douglas are visualized for any pathology), followed by examining the whole peritoneal cavity. The hysteroscope was introduced into the cervical canal under vision.

The uterine cavity was distended with $0.9 \%$ normal saline and examined. Chromopertubation was done to check the patency of tubes by injecting dilute methylene blue through the intrauterine cannula. After the procedure, patient was transferred to postoperative ward and were discharged next day.

\section{RESULTS}

Present study included 200 patients of infertility. Of them, 118 patients were of primary infertility cases and 82 were of secondary infertility.

Table 1: Age distribution of patients.

\begin{tabular}{|lllll|}
\hline $\begin{array}{l}\text { Age group } \\
\text { (in years) }\end{array}$ & \multicolumn{2}{l}{$\begin{array}{l}\text { Primary } \\
\text { infertility }\end{array}$} & \multicolumn{2}{l|}{$\begin{array}{l}\text { Secondary } \\
\text { infertility }\end{array}$} \\
\hline $21-25$ & No. & \% & No. & \% \\
\hline $26-30$ & 26 & 22.03 & 4 & 4.8 \\
\hline $31-35$ & 52 & 44.06 & 27 & 32.9 \\
\hline 36 And Above & 19 & 16.1 & 33 & 40.2 \\
\hline Total & 21 & 17.7 & 18 & 21.9 \\
\hline
\end{tabular}

The mean age of the patient was 29 years. In primary infertility cases, maximum number of patient (44\%) belonged to age group of 26-30 years whereas maximum number of secondary infertility cases $(40 \%)$ were under the age group of 31-35 years as given in Table 1 .

Table 2: Duration of infertility. 


\begin{tabular}{|lllll|}
\hline $\begin{array}{l}\text { Duration of } \\
\text { infertility } \\
\text { (in years) }\end{array}$ & $\begin{array}{l}\text { Primary } \\
\text { infertility }\end{array}$ & No. & \% & \multicolumn{2}{l}{$\begin{array}{l}\text { Secondary } \\
\text { infertility }\end{array}$} & No. \\
\hline $1-4$ & 28 & 23.7 & 36 & 43.9 \\
\hline $5-8$ & 40 & 33.8 & 28 & 34.1 \\
\hline $9-12$ & 34 & 28.8 & 10 & 12.1 \\
\hline 13 and above & 16 & 13.5 & 8 & 9.7 \\
\hline Total & 118 & & 82 & \\
\hline
\end{tabular}

Most of the patients among primary infertility (33.8\%) were having infertility duration ranging from 5-8 years, as against secondary infertility (43.9\%) who were infertile for 1-4 years as shown in Table 2 .

Most of the patients with infertility were asymptomatic. However, another symptoms present were asked for and tabulated as follows in Table 3.

Table 3: Complaints of patients.

\begin{tabular}{|lllll|}
\hline Complaints & \multicolumn{2}{l}{$\begin{array}{l}\text { Primary } \\
\text { infertility }\end{array}$} & \multicolumn{2}{l}{$\begin{array}{l}\text { Secondary } \\
\text { infertility }\end{array}$} \\
& No. & \% & No. & \% \\
\hline Asymptomatic & 73 & 61.8 & 75 & 91.4 \\
\hline Irregular cycles & 42 & 35.5 & 36 & 43.9 \\
\hline Dysmenorrhoea & 30 & 25.4 & 50 & 60.9 \\
\hline Dyspareunia & 42 & 35.5 & 25 & 30.4 \\
\hline Weight gain & 42 & 35.5 & 25 & 30.4 \\
\hline Hair growth & 11 & 9.3 & 13 & 15.8 \\
\hline Pelvic pain & 10 & 8.4 & 13 & 15.8 \\
\hline Discharge & 30 & 25.4 & 36 & 43.9 \\
\hline
\end{tabular}

Findings on laparoscopy and hysteroscopy are given in Table 4 and Table 5. Among 200 patients, 102 (51\%) had absolutely normal laparoscopic findings.

Table 4: Laparoscopic findings of patients.

\begin{tabular}{|lll|}
\hline Laparoscopic & Infertility & \\
\hline findings & No. & \% \\
\hline Normal & 102 & 51 \\
\hline BTB* & 20 & 10 \\
\hline UTB $^{*}$ & 48 & 24 \\
\hline Infections (TB $*)$ & 31 & 15.5 \\
\hline PCOS* & 52 & 26 \\
\hline Endometriosis & 64 & 32 \\
\hline Fibroid & 17 & 8.5 \\
\hline Pelvic adhesions & 24 & 12 \\
\hline Simple cyst & 18 & 9 \\
\hline Others & 22 & 11 \\
\hline
\end{tabular}

*BTB- Bilateral tubal block, *UTB-Unilateral tubal block, *TBTuberculosis, *PCOS-Polycystic ovarian syndrome

The most common abnormality found on laparoscopy was endometriosis (32\%). Among uterine factors, number of patients with fibroids were observed in 17 (8.5\%) patients followed by congenital anomalies in $6(3 \%)$ patients. Among the tubal factors, bilateral tubal occlusion was observed in 20 (10\%) cases whereas unilateral block in 48
(24\%). Bilateral polycystic ovaries were observed in 52 (26\%) cases among ovarian pathologies. In present study, typical pelvic adhesions were found in among 24 (12\%) patients and about $31(15.5 \%)$ patients had Koch's abdomen. Other significant findings were cysts, perihepatic adhesions, etc.

Table 5: Hysteroscopic findings of patients.

\begin{tabular}{|lll|}
\hline Hysteroscopic findings & Infertility & \\
\hline Normal & 153 & \%o. \\
\hline Periosteal adhesions & 14 & 76.5 \\
\hline Polyps & 7 & 3.5 \\
\hline Stenosis of internal os & 3 & 1.5 \\
\hline Deep-seated ostia-small cavity & 4 & 2 \\
\hline Septum & 3 & 1.5 \\
\hline Fundal adhesions & 2 & 1 \\
\hline Endometritis & 8 & 4 \\
\hline Endometrial hyperplasia & 6 & 3 \\
\hline
\end{tabular}

Majority of patients (76.5\%) had normal hysteroscopic findings. Most common pathology found was periosteal adhesions (7\%). Other important findings were endometritis, polyps, septum, etc.

Among the various pathologies, ovarian pathology contributed the most (40\%), followed by tubal $(35.5 \%)$, pelvic $(21 \%)$ and uterine $(11 \%)$ pathologies as given in Table 6.

Table 6: Causes of infertility.

\begin{tabular}{|c|c|c|}
\hline \multirow{2}{*}{ Causes of infertility } & \multicolumn{2}{|c|}{ Infertility } \\
\hline & No. & $\%$ \\
\hline Ovarian & 80 & 40 \\
\hline Tubal & 71 & 35.5 \\
\hline Uterine & 22 & 11 \\
\hline Pelvic pathology & 42 & 21 \\
\hline
\end{tabular}

\section{DISCUSSION}

Role of diagnostic hystero-laparoscopy in current infertility management is debatable. In the 1990s, laparoscopy was the final step in the routine diagnostic approach for the evaluation of infertile couples (Rowe et al.1993). ${ }^{15}$

However, due to the advancement of new perspectives in assisted reproductive technology (ART), the process of evaluating infertile couples has changed. Currently, the most widely accepted approach to infertility is no longer based on diagnosing an exact aetiology.

The scope and the sequence of modern infertility evaluation focus on the most efficient and cost-effective tests. The investigation of infertile couples should be rapid and inexpensive, using minimally invasive tests (Gomel and McComb 2010). ${ }^{16}$ 
In 1997, Glatstein et al. reported that $89 \%$ of all reproductive endocrinologists in the USA routinely performed a laparoscopy in the diagnostic work-up of infertility. ${ }^{17}$ However, some investigators showed that diagnostic laparoscopy did not reveal any pathology or only minimal and mild endometriosis in $40-70 \%$ of all cases. $^{18}$

Among 200 patients, $102(51 \%)$ had absolutely normal laparoscopic findings and $153(76.5 \%)$ had normal hysteroscopic findings. The slightly higher percentage of normal findings in our study is because of a higher number of patients who have not been treated previously. The available literature on the role of laparoscopy merely focuses on 3 domains.

\section{Role in tubal pathology}

The clinical implications of an obstruction that is detected by HSG, include a high probability that the tube is open (approximately 60\%); however, when HSG shows patency, there is a low probability that the tube is occluded (approximately 5\%). In our study, tubal occlusion was seen in $24 \%$ (unilateral) and $10 \%$ (bilateral). Tubal pathology is significantly higher in our study, perhaps because of the higher incidence of tuberculosis in India. Regarding tubal occlusion, laparoscopy is recommended when HSG reveals a bilateral obstruction.

Laparoscopy can be postponed until at least 10 months after a normal patency or unilateral obstruction is revealed by HSG, particularly in females 36 years of age with normal ovarian reserves. Generally, the rate of treatmentindependent pregnancy is highest when both tubes are patent, according to HSG (Speroff and Fritz 2011). ${ }^{5}$ However, laparoscopy provides a general view of the pelvic organs and any bowel and/or pelvic peritoneal adhesions; therefore, this procedure may be used to identify milder forms of distal tubal occlusive diseases, such as fi mbrial agglutination or fi mbrial phimosis.

\section{Role in endometriosis}

Laparoscopy can detect minimal and mild endometriosis, which may not be detected on pelvic ultrasonography (USG) or HSG. Most importantly, at the time of diagnosis, diseases may be treated laparoscopically. The most common pelvic pathology in our study was Endometriosis (32\%), whereas tubal pathology was observed in $35.5 \%$ cases (Table 4 and 6). In a cohort study, Lessey et al. also found a high prevalence of endometriosis in patients with unexplained infertility. ${ }^{11}$ In a similar study, Poncelet et al. found that laparoscopy revealed pelvic pathology in 95 out of 114 patients. Of those, 72 had endometriosis, 46 pelvic adhesions, and 24 tubal disease. ${ }^{19}$

\section{Role in pelvic adhesive diseases}

Pelvic adhesive diseases are caused by pathological factors (endometriosis or pelvic infection) tubal fimbriae function, which primarily determines fertility, cannot be properly demonstrated by HSG. Even in the presence of open fallopian tubes, as detected by HSG, deficient fimbrial movement that is inadequate for ovum retrieval may cause infertility. Therefore, laparoscopy is an exceptional test that can determine fimbrial function in addition to the patency of tubes, which is vital for ovum retrieval (Speroff and Fritz). ${ }^{5}$

In a retrospective study, Capelo et al. performed diagnostic laparoscopy in 92 patients after four failed cycles of ovulation induction treatment with clomiphene citrate. Laparoscopic findings were strictly normal in only $36 \%$ of cases, whereas endometriosis and/or pelvic adhesions were observed in $50 \%$ and $33 \%$, respectively. The authors concluded that laparoscopy continues to be a useful tool in the work-up of an infertile couple but regrettably did not present any pregnancy rates following laparoscopic surgery. ${ }^{20}$ These results are comparable to that obtained in our study.

Goldman et al found that in the absence of findings during an unexplained infertility evaluation, routine laparoscopy was not necessary. The majority of patients who proceed to treatment will become pregnant. However, this study compared pregnancy outcomes in women with unexplained infertility rather than findings at laparoscopy. ${ }^{21}$ Shimizu et al. concluded that diagnostic laparoscopy should be offered as an option for younger patients who desire spontaneous pregnancy because no significant difference was found in the cumulative pregnancy rate between patients proceeding to direct IVF and those doing so after laparoscopy. In the latter, however, the chance of spontaneous conceptions was higher. ${ }^{22}$

\section{Role of Hysteroscopy}

Few reports are available in literature which focuses on hysteroscopic findings along with laparoscopy. In many previous studies, no significant finding had been found on hysteroscopy. This is not surprising, as other authors have also demonstrated that a regular myometrial endometrial interface and homogeneous endometrial structure on transvaginal sonography indicated a normal endometrium and precluded the need for diagnostic hysteroscopy. ${ }^{12}$ In our study, $76.5 \%$ patients had normal fi ndings (Table 5). The most common pathology seen on hysteroscopy was periosteal adhesions (7\%), whose clinical significance is debatable. Endometrial polyps were seen in $3.5 \%$.

The timing of laparoscopy, too, has been a matter of debate. Although laparoscopy prior to initiating treatment looks attractive, the cost of this surgical procedure is high. Many clinicians thus prefer to treat couples with unexplained infertility with a few cycles of stimulation with IUI before proceeding to laparoscopy. Whether laparoscopy should be performed after or before IUI was studied in a retrospective study designed by Tanahatoe et al. $^{23}$ 


\section{CONCLUSION}

Laparoscopy is not a routine part of the diagnostic approach for infertile couples. Every patient and clinical condition must be assessed individually. In conclusion, laparoscopy has been found to be a minimally invasive, more accurate and convenient procedure for diagnosis of infertility. It has revolutionized the management of infertility especially when patients have failed three or more cycles of IUI. Laparoscopy is helpful in diagnosing tubal diseases, adhesions, and blockage, infections, T.B, endometriosis and most worthy in secondary infertility with no risk factors. Even though the outcome in terms of clinical pregnancy may not be significant as per previous studies, laparoscopy may help prevent unnecessary treatment wherein success rates are low. Clinicians should consider the option of diagnostic laparoscopy before IUI in patients with a history of pelvic infection, ectopic pregnancy, tubal surgery or symptoms of endometriosis. In patients with a history of tuberculosis or severe pelvic infection, laparoscopy should be considered as a first-step approach instead of HSG because in these clinical conditions, tubal morphology and fimbrial functional capacity are more important than demonstrating tubal patency.

Due to safety, high yield, lower complications and cost effectiveness laparoscopy should be recommended in all cases of infertility. Further well-controlled prospective randomized trials are required to evaluate the effects of diagnostic laparoscopy after failed ovulation induction, failed ovarian stimulation with IUI or failed ART cycles.

\section{ACKNOWLEDGMENTS}

Authors would like to thank all the patients recruited in the study and all the members of the Department of Obstetrics and Gynecology, MGM Hospital, Patna.

Funding: No funding sources

Conflict of interest: None declared

Ethical approval: Not required

\section{REFERENCES}

1. Dyer SJ. International estimates on infertility prevalence and treatment seeking potential need and demand for medical care. Hum Reprod. 2009;24(9):2379-80.

2. Yu SL, Yap C. Investigating the Infertile Couple. Ann Acad Med Singapore. 2003;32:611-4.

3. Mohapatra P, Swain S, Pati T. Hysteroscopic tubal cannulation: our experience. J Obstet Gynaecol India. 2004;54(5):498-9.

4. Olajide AA. The role of laparoscopy, hysteroscopy and falloposcopy in tubal causes of infertility. Tropical J Laparo Endoscopy. 2010;1(1):19-23.

5. Speroff L, Fritz MA. Clinical gynecologic endocrinology and infertility. $8^{\text {th }}$ ed. Philadelphia: Lippincott, Williams and Wilkins;2011:1137-91.
6. Crosignani PG, Rubin BL. The ESHRE Capri Workshop Group. 2000. Optimal use infertility diagnostic tests and treatments. Human Reprod. 2000;15:723-32.

7. Boivin J, Bunting L, Collins JA, Nygren KG. International estimates of infertility prevalence and treatment -seeking: potential need and demand for infertility medical care. Hum Reprod. 2007;22:150612

8. Aflatoonian A, Seyedhassani SM, Tabibnejad N. The epidemiological and etiological aspects of infertility in Yazd province of Iran. Iranian J Reprod Med. 2009;7:117-22..

9. Rehana R, Majid SS. Aetiological factors of infertility. J Postgrad Med Inst. 2004;18:166-71.

10. Reiter RC. Evidence based management of chronic pelvic pain. Clin Obstet Gynecol. 1998;41:422-35.

11. Lessey BA, Forstein DA, Miller PB, Egbuniwe MN, Dodds R. Laparoscopic surgery improves outcome and diagnostic accuracy in unexplained infertility. Fertil Steril. 2010;94:S38.

12. Nayak PK, Mahapatra PC, Mallick JJ, Swain S, Mitra $\mathrm{S}$, Sahoo J. Role of diagnostic hystero-laparoscopy in the evaluation of infertility: A retrospective study of 300 patients. J Hum Reprod Sci. 2013;6:32-4.

13. Makled AK, Farghali MM, Shenouda DS. Role of hysteroscopy and endometrial biopsy in women with unexplained infertility. Arch Gynecol Obstet. 2014;289:187-92.

14. Jayakrishnan K, Koshy AK, Raju R. Role of laparohysteroscopy in women with normal pelvic imaging and failed ovulation stimulation with intrauterine insemination. J Hum Reprod Sci 2010;3:20-4.

15. Rowe PJ, Comhaire FH, Hargreave TB, Mahmoud AMA. WHO manual for the standardized investigation of the infertile couple. Cambridge: Cambridge University Press; 1993.

16. Gomel V, McComb PF. Investigation of tubal and peritoneal causes of infertility. In: Gomel V, Brill AI, editors . Reconstructive and reproductive surgery in gynecology. $1^{\text {st }}$ ed. London: Informa Healthcare. 2010:243-59.

17. Glatstein IZ, Harlow BL, Hornstein MD. Practice patterns among reproductive endocrinologists: Th e infertility evaluation. Fertil Steril. 1997;67:443-51.

18. Bosteels J, Van Herendael B, Weyers S, D'Hooghe T. Th e position of diagnostic laparoscopy in current fertility practice. Hum Reprod Update. 2007;13:47785.

19. Poncelet C, Bonneau C. Sifer C, Chanelles O. Interest of laparoscopy for Unexplained Infertility. Fertil Steril. 2011;96:S148-9.

20. Capelo FO, Kumar A, Steinkampf MP, Azziz R. Laparoscopic evaluation following failure to achieve pregnancy after ovulation induction with clomiphene citrate. Fertil Steril. 2003;80:1450-3.

21. Goldman MB, MacKenzie TA, Regan MM, Alper MM, Thornton KL, Reindollar RH. The role of diagnostic laparoscopy in couples treated for 
unexplained infertility in the fast track and standard treatment (FASTT) trial. Fertil Steril. 2009;92(Suppl):S32-3.

22. Shimizu Y, Yamaguchi W, Takashima A, Kaku S, Kita N, Murakami T. Long-term cumulative pregnancy rate in women with unexplained infertility aft er laparoscopic surgery followed by in vitro fertilization or in vitro fertilization alone. J Obstet Gynaecol Res. 2011;37:412-5.
23. Tanahatoe S, Hompes PG, Lambalk CB. Accuracy of diagnostic laparoscopy in the infertility work-up before intrauterine insemination. Fertil Steril. 2003;79:361-6.

Cite this article as: Rai A, Mishra MG. Diagnostic hystero-laparoscopy in work-up of female infertility. Int J Reprod Contracept Obstet Gynecol

2017;6:2852-7. 